\title{
Teaching English as a Foreign Language through Literature
}

\author{
Mei-Ling Chen \\ Department of Applied English, HungKuang University, Taiwan
}

\begin{abstract}
This paper presents evidence that literature for children can be effectively used to acquire English as a foreign language in students of all ages. Students benefit from being challenged with language input that is slightly beyond their independent level of comprehension. This comprehensible input can be provided by listening to the reading or the telling of a story. Suggestions for practical applications of language acquisition and learning principles are included in five categories of activities using English language literature-story selection, listening, shared reading, independent reading, and drama.
\end{abstract}

Index Terms - literature, EFL learners, language acquisition

\section{INTRODUCTION}

It is well established that a rich language experience during the first years of life are essential for successful first language (L1) development (Chomsky, 1957; Heath, 2004; Wells, 1986). It is also accepted that listening to polished reading contributes to a command of English and development of vocabulary (Adams, 1990; Elley, 1989; Freeman \& Freeman, 2007; Short \& Harste, 1996). Further, children's literature has been found useful for development of second language acquisition for students of all ages (Neugebauer \& Currie-Rubin, 2009; Reid, 2002).

Students benefit from being challenged with language input that is slightly beyond their independent level of comprehension (Krashen, 1982). This can be provided by conversation or listening to the reading or the telling of a story. This notion of using literature for English as a Foreign Language (EFL) acquisition is not new. Quintilian (A.D. 35 - 95) advocated the use of Aesop's fables for acquiring Latin as a foreign language. Later, Erasmus (1466-1536) used pictures and then Comenius (1592-1670) wrote a picture book for acquiring Latin as a foreign language (Darian, 1972). This paper explores the efficacy of using quality literature for children for EFL acquirers of all ages.

\section{LITERATURE REVIEW}

\section{Qualities of Children's Literature}

It is difficult to define literature for children. In reality it is any book that is read to or by children. However, if a book is a Children's book, it usually has the following qualities (Temple, Martinez, \& Yokota, 2004):

"A child protagonist and an issue that concerns children" (p. 8) - often the central character is about the age of the intended reader although not always, as in the case of folktales.

"Straightforward story line" (p. 8) in a simple setting-books for younger children include only one or two main characters. They are simply told from character introduction, goal, problem, conflict, through resolution. Books for young adults have more complex story lines that more closely parallel adult books.

Simple vivid concrete language-young readers understand more of what readers do than what they say or think. Young adult readers can follow more complex language structures (Temple, Martinez, and Yokota, 2004).

These last two characteristics make children's literature ideal for English language learners. Quality children's literature shares the same characteristics as quality literature for other age categories. Authors of quality literature provide differing perspectives and broaden understanding of the world; provide an enjoyable story that does not overtly moralize; deal with significant truths about the human experience; the characters are true to life; the insights are at least accurate and maybe even wise; choose precise words; the plot is convincing; the characters are believable, and the descriptions are telling; and provide a total experience through the book that comes together for a satisfying whole - genre, characters, goals, conflicts, themes and illustrations (Temple, Martinez, and Yokota, 2004).

These qualities engage readers of all ages. Coupled with a straightforward story line and vivid, concrete language, children's literature can provide ideal materials for English language learning.

\section{Comprehensible Input}

Krashen (1982) posits that language acquisition and language learning are two distinct cognitive functions. Acquisition focuses on comprehension of language, while learning focuses on the rules of grammar, which produce correct speech. Both functions are necessary. Language acquisition input is most effective when it is natural, interesting, and understood (Krashen, 1982). Thus, rules of grammar are first intuitively acquired through meaningful language use and then later they can be formally learned. English language acquirers benefit from practice in listening comprehension. Students acquire a second language only when they are exposed to comprehensible input (Krashen, 1982), which is 
listening to or reading the target language that is a little beyond their current level of competence $(i+1)$. Providing learners with comprehensible input facilitates their natural language acquisition (Krashen, 1982).

\section{Early Foreign Language Scholars}

The work of early language educators contained elements that are compatible with this current theory on language acquisition. The famous language teacher of antiquity, Marcus Fabius Quintilian (A.D. 35 - 95), was born in Spain, but traveled to Rome as a young man. After an apprenticeship, he became an advocate and a teacher of rhetoric (Darian, 1972). His methodology for teaching Latin as a foreign language was to:

1. Read aloud an Aesop fables. Ask the students to retell the fable in their own words,

2. Later, write the fables, and

3. Students listened to poetry; then paraphrased it into prose (Darian, 1972).

Quintilian included literature and drew upon students' background knowledge in L1. It is understood that his greatest contribution to modern language instruction is that correctness is derived from the usage of the educated. This concept still plays an important part in determining standards of usage in modern English language teaching (Darian, 1972). When learning a foreign language, one wishes to learn the dialect that will offer the most opportunities. However today, we understand the value of less privileged dialects (Delpit, 1995).

Desiderius Erasmus (1466-1536) was a Dutch scholar who followed in the tradition of Quintilian in methodology and language - Latin. Erasmus advocated very little initial formal grammar instruction. The student should be exposed to historical and mythological stories, descriptions of plant and animal life illustrated by pictures (Darian, 1972). Erasmus said:

"I have no patience with the stupidity of the average teacher of grammar who wastes precious years in hammering rules into children's heads. For it is not learning rules that we acquire the power of speaking language, but by daily intercourse with those accustomed to expressing themselves with the exactness and refinement, and by copious reading of the best authors" (De Ratione Studii or Upon the Right Method of Instruction Part 3 Section 521C - 522A; cited in Darian, 1972, p.10).

Erasmus gave the language learning four points that are the cornerstones of modern language teaching:

1. Rules of usage are derived from an examination of the actual language as it is spoken.

2. The rules of grammar should be taught only after they have been acquired intuitively by reading or other means.

3. All grammar rules should be accompanied by examples.

4. Pictures should be used to illustrate new material whenever possible (Darian, 1972).

Following Erasmus, the most important language scholar of the time was Moravian Bishop Johannes Amos Comenius $(1592-1670)$. He believed that the experiences in the foreign language should draw upon the students' background knowledge, and he advocated using a controlled vocabulary. He differed with his contemporaries by urging teachers to present not just one meaning, but also multiple common meanings. Comenius wrote textbooks that were compatible with his instructional methods (Darian, 1972). His second textbook Orbis Pictus published in 1657 was a picture dictionary illustrated with woodcuts. Although it was written as a Latin textbook, it is considered the first informational book for children. This work was used as a textbook until the late 1700s (Temple, Marines, \& Yokota, 2004). A picture was placed on one page, while the facing page contained the text. Numbers in the text corresponded with numbers in the pictures to help with the readers understanding (Darian, 1972).

Comenius made the following argument in support of using pictures:

"If the objects are not present, the senses grow dull and flit hither and thither out of weariness. But when the objects are present, they [the students] grow merry, wax lively and willingly suffer themselves to be fastened upon them till [sic] the things be sufficiently discerned" (Darian 1972, p.14.)

Comenius continued the tradition started by Quintilian—one acquires language by hearing and reading, followed by learning the rules of grammar (Darian, 1972). It is interesting that much of these early scholars' work is still compatible with current language theory.

\section{APPlications of Literature}

Elley, Cutting, Mangubhai, and Hugo (1996) report on literature based English as a Second Language (ESL) programs in Fiji, Singapore, Sri Lanka, and South Africa. In all cases high interest illustrated books were donated to schools in each country. With variations in each country, teachers were educated to use these books frequently in productive activities, such as shared reading, paired reading, and independent silent reading. In shared reading (Holdaway, 1979), teachers use big books or class sets of trade books to guide students through a reading experience. Teachers discuss the covers, titles, selected illustrations, and content. Students join in the reading when they can, such as reading a familiar repeated phrase. Students also read to each other in paired reading, and silently by themselves. Teachers initially write for students, and then write with students. Finally, students do their own writing.

Non-participating schools used commercial English language basal programs. In all cases students at participating schools outperformed those at nonparticipating schools. There were a variety of English assessments and anecdotal reports supporting these findings. A common thread of these programs was the strong impact on children's language acquisition (Elley et al., 1996).

Story Selection 
Matching the reader/listener to the optimal text is an essential art of language and literacy teachers. Language acquirers do not practice language void of meaning. Language, unless reduced to nonsense syllables or individual phonemes, cannot be isolated from meaning. Thus, language is unavoidably about something. This reality is a boon for language educators and acquirers, as working with texts of personal interests can be highly motivational (McCormick, 2007). Language teachers can draw from any conceivable topic or genre that is of interest to acquirers. The importance of this point cannot be overemphasized.

In the late 1990s an impressive body of literature on motivation found its way into the reading community (Alexander and Fox, 2004). The research on this topic has been growing for several decades. We now have evidence that learners' interests, goals, and beliefs about their own language abilities impact the success they experience as language acquirers (McCormick, 2007). This has led to the concept of the engaged or motivated language user (Alexander \& Fox, 2004). The concept of student choice is an important part of motivation, however students often do not know the array of options that are available to them. This is where well-read teachers, who intimately know their students' interests and cultural and linguistic backgrounds can be of help.

Using stories that English language acquirers already know in their native language takes advantage of their background information. This story knowledge supports acquirers' English comprehension (Vardell, Hadway, \& Young, 2006).

\section{Listening}

Listening to an accomplished reading of interesting texts offers benefits for second language acquisition as well as reading development (Neugebauer \& Currie-Rubin, 2009). Besides providing a positive experience using the target language, listening helps develop vocabulary and understanding of literary devices. There are also benefits in following along in the text while listening to the story. This listening while-reading technique is also beneficial if used repeatedly on the same story (Rasinski, 1989). Readers/listeners gain insights and understand themes more thoroughly following multiple readings of the same text (Frost, 1990).

In preparation for reading aloud, it is essential that the text be read prior to the performance. There are often unexpected twists that an author may take in sentence construction. Young acquirers also need preparation for the listening session. It is important to remove immediate distractions from them (Lynch-brown \& Tomlinson, 2008). After reading the title and showing the cover and the initial illustrations, ask the students to make predictions of what will follow. Since listening to a new language takes a high level of mental energy, do not overtax the listeners. Read clearly and fairly slow with a relaxed voice, but do not distort the natural rhythm of the story (Reid, 2002).

\section{Shared Reading}

Shared reading refers to two or more people sharing the reading of a text. In an activity called echo or shadow reading, students are asked to read aloud along with the teacher. The teacher reads aloud at slow pace, but faster than the students can read by themselves. The students' reading should lag slightly behind the teacher's. This helps with learning pronunciation and phrasing. This technique is helpful even for advanced students, because of the word pronunciation support. Resist the temptation to stop at each unfamiliar word. Students should begin to cluster meaning into chunks or phrases. The ultimate goal is for the students to summarize an entire paragraph or page-length passage in their own words after one reading (Reid, 2002).

A follow-up activity for further development is shared sentence reading. The teacher reads one sentence, immediately followed by the student reading the same sentence. Do not translate individual words, but keep the translation general to the sentence. Focus students on just getting the gist of the story. At the end of each paragraph, the teacher should reread the paragraph aloud before continuing to the next. This facilitates a review the paragraph before moving the next. Repeat this set of activities. Encourage the more advance learners to give a general translation for the less advanced learners (Reid, 2002).

Once a book is completed using the above techniques, the teacher may read the book again out aloud, encouraging the students to follow along. Students should not worry about the details. They should focus on getting the general structure of the story and the normal flow and rhythm of English. An audiotape can be useful for this activity. It is often helpful to construct a chart of the events that take place in the story (Reid, 2002).

\section{Independent Reading}

Students should be given many opportunities to read independently. Materials should be selected that are at the students' independent English reading level. This means that the student recognizes $99 \%$ of the words and comprehends $90 \%$ of the passage content (McKenna \& Stahl, 2003). Reading levels are not immoveable ceilings. They vary with the readers' interests and expertise. If a reader is interested in extreme sports, the reading level will be higher when reading materials related to extreme sports (McCormick, 2007).

There are at least two ways to structure independent reading that maximize language development. The first is to provide a few questions for the reader to answer at periodic intervals through the text (Reid, 2002). These should be general questions that focus the reader on understanding the theme or the gist of the reading. It is important to craft the questions so the readers will be successful. The goal is to build reader confidence. Good questions might be: What has happened so far? Who are the main characters? Do you think the protagonist will succeed? Why? Challenge intermediate students slightly more with questions such as these: What obstacles has the protagonist faced in reaching the goal? What cause-and-effect relationships do you see (Reid, 2002)? 
Another way to structure independent reading for all levels of readers is to use a variation of think aloud protocol. Place a red dot or other symbol in the text periodically at strategic spots. When readers come to these markers they must convey what they are thinking by speaking out loud or writing their thoughts down on a separate sheet of paper (Tierney \& Readence, 2000). Thinking about the text nudges readers to attend to the meaning of the text, increasing comprehension (Pressley, \& Afflerbach, 1995), and provides meaningful English language practice.

A post reading response to independent reading can be beneficial as another opportunity to use English in a meaningful way. One such engagement is the Onepager (Personal Communication Bobbi Jentes Mason March, 1995). This consists of a creative response that is limited to one page, which includes the following elements: one visual element (image), two quotes from the reading, one reflective statement from the reader or a related quote form another source, and one personal comment from the reader. These elements are arranged on one page to present a creative and thoughtful response to the reading.

Collecting, discussing, and analyzing common proverbs between L1 and L2 can help learners understand the historical and cultural background of the target language. Proverbs highlight the values held by the cultures of each language. This activity can lead acquirers to identify cultural similarities and differences (Kuo \& Lai, 2006).

\section{Drama}

There are three simple forms of drama that can be enjoyable ways to use English. Drama provides players alternative perspectives and increases comprehension.

Story theater. The simplest of these classroom drama activities is story theater. The suitability of this drama form is limited to young children. There is no audience for this drama. The value comes from participation. The teacher reads aloud the story, while the students pantomime the action. There are no props or sets. The teacher usually assigns the characters to groups of students. Stories filled with action and minimum dialogue are best for story theater (Temple Martinez, Yokota, 2004).

Creative Drama. Players of creative drama enact stories without narration. The story is conveyed only through action and dialogue. The dialogue is adlibbed. Players know story events and make up their own lines as they are performing. There may be a few props - card stock headbands for animal horns or crowns. Stories with extensive dialogue and action work best for Creative Drama. There should only be a minimum of narration (Temple Martinez, Yokota, 2004).

Role-play. As a related activity, Kuo and Lai (2006) recommend role-play from a socio-cultural approach. Students can dramatize actual incidents, which caused cross-cultural misunderstanding. In this way, the role-play prepares students to overcome miscommunication problems using the target language.

Readers Theater. Readers Theater relies solely on the players' voices to convey the story. As the name implies, the players read a script. They only convey their characters through their voices. This form of drama is a performance. Therefore, players practice voice, inflection, and prosody until their parts are perfected. Players can collaborate, along with the teacher's assistance, to identify the optimum tone of voice for the sly, miserly, and dishonest, as well as the benevolent, good-natured, honest, humorous, and heroic characters. Players must read with expression and energy. Preferably they perform while sitting raised on stools, but chairs can be substituted. Stories filled with dialogue, but little narration and action are best for Readers Theater. Stories with lots of action can be adapted for use.

\section{CONCLUSION}

Practitioners understand that language is best acquired from interesting comprehensible input that is within meaningful contexts (Krashen, 1982). It has long been advocated that grammar is best acquired intuitively by listening to speech and good literature, by reading, or by engaging in meaningful conversations before rules of grammar are learned (Darian, 1972). Based upon these assumptions, the paper suggested literary instructional activities that provide comprehensible input (Krashen, 1982), develop intuitive English speech patterns, and benefit reading development (Adams,1990; Short \& Harste, 1996). The evidence presented here suggests that meaningful instruction married to quality literature for children can be an effective approach to second and foreign language acquisition.

\section{REFERENCES}

[1] Adams, M. J. (1990). Beginning to Read: Thinking and Learning about Print. Cambridge, MA: MIT Press.

[2] Alexander, P. A., \& Fox, E. (2004). A Historical Perspective on Reading Research and Practice, in Theoretical Models and Processes of Reading (5th ed.), ed. R. Ruddell \& N. Unrau et al. Newark, DE: International Reading Association.

[3] Chomsky, N. (1957). Syntactic Structures. The Hague, Netherlands: Mouton.

[4] Darian, S. G. (1972). English as a Second Language: History Development and Methods of Teaching. Norman, OK: University of Oklahoma Press.

[5] Delpit, L. (1995). Other People's Children. New York: New Press.

[6] Elley, W. B. (1989). Vocabulary Acquisition from Listening to Stories. Research Reading Quarterly, 24, 174-187.

[7] Elley, W., Cutting, B., Mangubhai, F., Hugo, C. (1996). Lifting Literacy Levels with Story Books: Evidence from the South Pacific, Singapore, Sri Lanka, and South Africa. Paper presented at the World Conference on Literacy, Philadelphia, PA, March 1996. ERIC database. (ED416441).

[8] Freeman, D., \& Freeman, Y. (2007). "Bienvenidos" "Huanying” "Welkom” "Tuloy Kayo" Welcome.” Instructor, 117(1), $52-55$. 
[9] Frost, S. B. (1990). Increasing Reading Achievement through Repeated Paired Reading Practicum Paper. Nova University. ERIC database (ED323508).

[10] Heath, S. B. (2004). Ways with Words: Language, Life, and Work in Communities and Classrooms. New York: Cambridge University Press.

[11] Holdaway, D. (1979). Independence in Reading. Auckland, New Zealand: Ashton Scholastic.

[12] Krashen, S. (1982). Principles and Practices in Second Language Acquisition. Oxford: Pergamon.

[13] Kuo, M. M., \& Lai, C. C. (2006). Linguistics across Cultures: The Impact of Culture on Second Language Learning. Journal of Foreign Language Instruction, 1(1), 1-10.

[14] Lynch-Brown, C., \& Tomlinson, C. M. (2008). Essentials of Children's Literature (6 $6^{\text {th }}$ ed.). Boston: Pearson Education.

[15] McCormick, S. (2007). Instructing Students Who Have Literacy Problems (6th ed.).Upper Saddle River, NJ: Pearson Prentice Hall.

[16] McKenna, M. C., \& Stahl, S. A. (2003). Assessment for Reading Instruction. New York: Guilford Press.

[17] Neugebauer, S. R., \& Currie-Rubin, R. (2009). Reading-alouds in Calca, Peru: A Bilingual Indigenous Context. Reading Teacher, 62, 396- 405 .

[18] Pressley, M., \& Afflerbach, P. (1995). Verbal Protocols of Reading: The Nature of Constructively Responsive Reading. Hillsdale, NJ: Erlbaum.

[19] Rasinsky, T. V. (1989). The effects of repeated reading and repeated listening while reading on reading fluency. Research report, Kent State University. Retrieved from ERIC database. (ED304666).

[20] Reid S. (2002). Book Bridges for ESL students: Using Young Adult and Children's Literature to Teach ESL. Lanham, MD: Scarecrow Press.

[21] Short, K., Harste J. C., \& Burke, C. L. (1996). Creating Classrooms for Authors and Inquirers. Portsmouth, NH: Heinemann.

[22] Tierney, R. J., \& Readence, J. E. (200). Reading Strategies and Practices: A Compendium (5th ed.). Boston: Allyn and Bacon.

[23] Temple, C., Martinez, M., \& Yokota, J. (2004). Children's Books in Children's Hands: An Introduction to Their Literature. San Francisco: Pearson Allyn and Bacon.

[24] Vardell, S. M., Hadway, N. L., \& Young, T. A. (2006). Matching Books and Readers: Selecting Literature for English Learners. Reading Teacher, 59(8), 734-741.

[25] Wells, G. (1986). The Meaning Makers. Portsmouth, NH: Heinemann.

Mei-Ling Chen is currently an Associate Professor in Department of Applied English at HungKung University in Taiwan. Her research interests include teaching materials and methods, second language acquisition, language learning strategies and learning styles. 